\section{The rewards and challenges of developing a brochure to teach women about needle localization/biopsy}

By Judith MacPhail

\section{Abstract}

The move toward outpatient surgery and early discharge requires oncology nurses to rely on printed materials to reinforce or even replace existing patient education programs. This article describes the process used to develop a brochure to educate women about the needle localization and biopsy procedures. A critical analysis of the brochure development process is presented, including the needs assessment, target population, purpose and objectives, content, interdisciplinary reviewing mechanism, evaluation, printing, use and lessons learned.

\section{Introduction}

Breast cancer is the leading cause of cancer deaths in Canadian women (Health and Welfare Canada, 1992). With no prospects for primary prevention in the foreseeable future, there has been dramatically increased interest and emphasis on early detection of this disease (Chart \& Taylor, 1991). Widespread organized screening, using mammography as one tool, has increased the discovery of non-palpable breast lesions. Greater detection of breast abnormalities, combined with advances in technology have resulted in an increased demand for needle localization/biopsy. The need for this procedure will only increase in the future as the value of early detection becomes more widely known.

\section{Background to the project}

The breast diagnostic clinic (BDC) was prompted by the expressed needs of physicians and of women in the community for expeditious resolution of breast problems, evaluation of breast cancer risk, and surveillance for breast cancer. In October of 1990 , the Toronto-Bayview Regional Cancer Centre (T-BRCC) BDC was established. The new ideas involved in this diagnostic service are consistent with the early detection mandate of the T-BRCC and the health care goals of Ontario

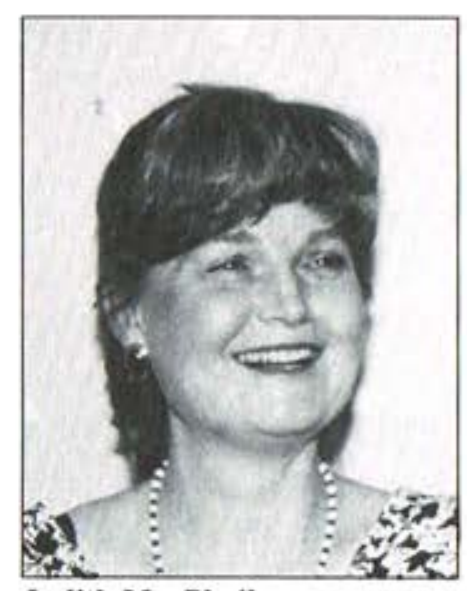

Judith MacPhail for the 1990s. (Premier's Council on Health Strategy, 1991) Referrals come from all levels of health care providers (eg. physicians, nurses, $\mathrm{x}$-ray technologists). Approximately 325 new patients are seen annually. The BDC provides services on an outpatient basis only, but radiological and surgical services are shared with an adjacent large urban teaching hospital.

This early detection program was founded upon two key assumptions. First, the strongest predictor of outcome in breast cancer is the stage of disease at diagnosis (Chart \& Taylor, 1991). Second, the philosophy statement of the T-BRCC commits to the belief "that our patients are active participants in their treatment team, with the right to information and a vital involvement in their own care" (Moffat, 1991).

The initial step in the surgical management of a breast mass is a tissue diagnosis. Needle localization is the best tool for identifying non-palpable breast lesions (Chart \& Taylor, 1991). It involves placing a very thin needle and guide wire into the breast under mammographic visualization to locate the lesion. The wire is left in place until it is removed by the surgeon at the time of the biopsy.

The anxiety response of women is related to detection of a breast abnormality that cannot be felt, and subsequent recommendation for biopsy. Forgotten or poorly recalled verbal instructions often result because of this anxiety.

The centre's commitment to provide patients with pertinent information and the professional caregivers' observations of barriers to meeting this goal led to the decision to provide written information on needle localization/biopsy.

\section{Brochure development}

\section{Needs assessment}

The need for an educational tool about needle localization/biopsy was identified by the primary nurse in the BDC. Nurses can have a major impact on positive patient reactions to this diagnostic procedure simply by providing patient education.

A review of the literature revealed one brochure of this type, "Questions and Answers about Needle Localization" (Habegger \& Ellerhorst-Ryan, 1988). This brochure discussed the what, why, who and how of the needle localization in simple words and a brief format. No brochure was identified which included both the needle localization and biopsy procedure. Nothing in the literature provided all the information that the BDC patients were requesting. Nor was there a brochure that was congruent with the way the procedure was performed in this centre.

\section{DÉFIS ET RÉCOMPENSES DE L'ÉLABORATION D'UNE BROCHURE VISANT À RENSEIGNER LES FEMMES SUR LA BIOPSIE ET LA POSITION DE L'AIGUILLE}

\section{ABRÉGÉ}

La tendance actuelle vers les consultations chirurgicales externes et les congés précoces exigent des infirmières qu'elles s'appuient sur des documents imprimés pour renforcer ou même remplacer les programmes existants d'enseignement aux patients. Cet article décrit le processus employé pour mettre au point une brochure renseignant les femmes sur les procédures de la biopsie et la position de l'aiguille. II présente une analyse critique du processus de mise au point de la brochure y compris l'évaluation des besoins, la population cible, l'objet et les objectifs, le contenu, le mécanisme de révision interdisciplinaire, l'évaluation, l'impression, l'emploi et les leçons que l'on a pu en tirer.

Judith MacPhail, RN, BAA(N) is primary nurse, breast diagnostic clinic, Toronto-Bayview Regional Cancer Centre, Toronto, Ontario. 
At the T-BRCC, needle localization/biopsy is completed as an outpatient procedure in the adjacent hospital. The need for pre-procedure patient education during the clinic appointment, as well as preparation for the intra-procedural activities and self-care at home is evident. Difficulties in scheduling operating room time sometimes resulted in a delay of up to six weeks between the booking and the actual procedure. Therefore, written reference materials were required to reinforce verbal instructions. In the past, the outpatient procedures unit provided an explanatory pamphlet. The content, however, covered basic surgical routines and was not specific to the needle localization/biopsy.

While at the clinic, women repeatedly asked an assortment of questions about needle localization/biopsy. Questions included: "How do I prepare for the procedure?" "What sensations might I experience?" "What restrictions will I have when I return home?" "When will I know the results?" In addition, logistical questions such as date, time, location, room and telephone numbers were a concern. These questions formed the basis of the brochure.

\section{Target population}

The target population for the brochure is women who have non-palpable breast abnormalities identified by mammography. A review of the 1986 census data for the catchment area of the hospital indicated that $25.7 \%$ of the population held a university degree, while only $7.2 \%$ of the population had lower than a grade 9 education. (Ellis, 1992) Considering this high level of formal education, a reading level of grade 10 seemed appropriate for the brochure.

\section{Purpose and objectives}

The purpose in creating the brochure was to provide women with simple, readable, brief, accurate, comprehensive and sequential information about the entire process of the needle localization/biopsy. One document was sought which would explain the rationale of the procedure, pre-procedure work-up, intra-procedure activities, post-procedure and self-care considerations and follow-up clinic visit. As this brochure was the first patient education material that had been written at the new BDC, it was to be the gold standard for subsequent literature development.

\section{Content}

The style and some of the content of the brochure were modelled after the brochures developed by Habegger and Ellerhorst-Ryan (1988) and the outpatient procedures unit of Sunnybrook Health Science Centre, University of Toronto (1988). The Habegger brochure was amplified and tailored to the T-BRCC setting by including information listed in Table One. The who, what, when, why and how questions about the procedures were answered. Addressed, as well, were topics such as patient sensations, procedure length, restrictions at home, and time when the results would be known.

Women commonly requested a notation of the date, time and location of the procedure and the reception and surgical recovery telephone numbers. Therefore, blank spaces were left in the brochure to record this information. An individual element was added in the form of a nurse's name and telephone number to call for more information.

The patient undergoing needle localization/biopsy must interact with four separate areas: The BDC, the surgeon's office, radiology and outpatient surgery. Previously, instructions for outpatient surgery were distributed separately by the surgeon's secretary two weeks prior to the date of the procedure. Gaps in communication frequently occurred. For this reason, the entire needle localization/biopsy process is now included in one package. Furthermore, the sequencing of the questions and answers is organized to follow the logical order of events. To obtain a sense of this logical sequence of events, the primary nurse followed several patients through the procedures, took notes and validated impressions with both the patients and caregivers.

\section{Interdisciplinary reviewing mechanism}

Accuracy and comprehensiveness were major objectives in the development of the brochure. A review of the brochure by all caregivers involved in the procedures was seen as critical to the successful outcome of the project. The reviewers included staff from all four areas of the centre, nurses, radiologists, surgeon, $\mathrm{x}$-ray technologists, medical coordinator of the BDC, and booking/reception clerks.

The BDC primary nurse was the editor of the brochure and coordinated the project. A first draft was submitted to all the reviewers for their comments and suggestions regarding its format, content, accuracy, sequence and readability. A return date for the critique was given and each reviewer eventually responded. The critiques were incorporated in a second draft of the brochure and re-submitted to each reviewer for comment. In total, there were three drafts reviewed prior to the final version. The reviewing process took nine months to complete.

From an editorial perspective, the most challenging area on which to obtain consensus was the answer to the question of "How is the needle localization performed?" The reviewers experienced difficulty in finding a balance between too much technical information, which might increase patient anxiety, and too little information, which would render the explanation meaningless. The radiologists who worked at the BDC had their own variations on the technique used in the needle localization procedure. As well, the radiologists and $x$-ray technologists stressed the importance of generalizing this section so that they could individualize the needle localization to each patient, and use the brochure as a springboard to their pre-procedure discussion with the patient. The wording of the brochure needed to reflect the different approaches without sacrificing accuracy.

\section{Evaluation}

The evaluation of the brochure involved both patients and professional colleagues. The T-BRCC patient education committee provided the latter.

After the final draft was accepted by the reviewers and prior to translation and printing, the brochure was pre-tested by 10 patients. The objectives for the development of the brochure served as the basis of the evaluation questions. (See Table Two) This assessment was done by patients who had completed the procedure, prior to their return clinic appointment. A written evaluation and follow-up telephone call by the BDC primary nurse were the methods used.

The immediate patient reaction to the brochure was favourable. The patients judged the brochure to be accurate in terms of content and easy to read. Under the additional comments section of the evaluation form,

Table One: Content areas addressed in the " $Q$ \& A about Needle Localization/Biopsy" brochure

- Why is it done?

-What is a needle localization?

- How do I prepare for a needle localization?

- Who performs the procedure?

- How is it performed?

- What sensations might I experience during the procedure?

- How long does all this take?

-When will the guide wire be removed?

- What restrictions will I have when I return home?

- When will you know the results?

- For more information, call at RN

- Appointment information; date, time, place.

*If you would like to receive a copy of the brochure, please contact the author. 
some patients requested post-operative instructions, usual side effects of the procedure (cg. bruising and numbness around the wound), the information condensed to one sheet, and a map or room numbers of the exact location for the procedure. All of these suggestions were incorporated into the brochure.

The emphasis of the professional colleague evaluations was readability, wording, copyright, institutional acknowledgement and conformity with existing standards of T-BRCC written patient education material. Meade and Wittbrot (1988) warn that materials that are difficult to read or understand serve little purpose. Materials for patient education that are distributed and not understood pose a health hazard for the patient and a liability for the health care worker (Meade \& Wittbrot, 1988). Approval by the patient education committee was achieved with only minor changes in wording.

\section{Teamwork: The rewards and challenges}

The benefit of using the team approach to developing the brochure was the fostering of professional collaboration and education, increasing everyone's understanding of each member's role and responsibilities during the procedure. Accuracy was improved because the brochure contained the perspective of each team member. Compliance in the use of the brochure as a teaching aid was enhanced because the users were co-authors. Ownership proved to be a valuable motivator.

The main drawback of team writing was the length of time it took to complete the project; one year from genesis of the idea to finished product. Furthermore, as the number of drafts of the brochure increased, the enthusiasm of the reviewers decreased. The time spent by the reviewers on this project, which was an addition to their normal workload, was considerable.

From the perspective of the editor, the main challenge was conflict resolution and reaching a consensus. Negotiating skills were required. Many times, matters were resolved by focusing on the overview of the procedure rather than specific details. Discovering the underlying concern of the reviewer about that particular section of the script was helpful.

Process issues such as communication and decision-making were key to team writing, but very time-consuming for the editor. At times, the editor served as a "lightning rod" for team members' feelings, beliefs and values. Although there may have been opposing perceptions among the reviewers, the differences were worked through in a constructive fashion. Viewing the differing opinions as an opportunity and not as criticism was helpful. Differing opinions stimulated an informal evaluation of the existing procedure, and produced an accurate, comprehensive and creative document. All in all, extremely positive outcomes resulted from the tension.

\section{Brochure production}

As suggested by patients, the format for the brochure was one sheet, with questions in boldface type followed by the answer. The accordion-style folding of the brochure was done so that it could fit easily into a purse or briefcase and thus accompany the patient as quick reference material through the various stages of the procedure. Key points such as the name of the patient, the date and time of the procedure were highlighted by framing the section. Changeable items such as the nurse's name and telephone number were left blank.

The Ontario French Languages Services Act of 1986 promises that all government ministries and agencies must provide all information directed

\section{Table Two: Patient evaluation questions}

1. How well did this booklet prepare you for the procedure? very good good fair not very well

2. Which information was of most value to you?

3. Which information was of least value to you?

4. Was there anything that happened in the procedure that was not explained?

5. What suggestions would you make to improve the booklet?

6. Additional comments.

\section{Now published!}

JOURNAL

OF CANCER CARE

EDITORS: Ann Faulkner and Irene Scott

\section{THE JOURNAL OF CANCER CARE}

covers cancer care in hospitals, homes and hospices.

Prevention...early detection...acute, treatment-oriented care...continuing care...palliative care.

PLUS ...rehabilitation...psychological care, care of family members, support mechanisms for formal and informal carers...psychological impact of illness and attitudes to cancer...oncology education in Europe and the rest of the world.

\section{CONTENTS OF FIRST ISSUE INCLUDE:}

Childhood cancer: psychosocial needs Are they being met?/G Peace, C O'Keefe, A Faulkner, J Clark Shared care in paediatric oncology/K $R$ Muir, $S E$ Parkes, $R$ Boon, M C G Stevens, J R Mann Cancer Centre profile: The Christic Hospital/I Scott Quality of life/B M Traynor

Advances in symptom control for dysphagia and dyspnoea/N P Sykes

Health promotion:testicular self examination/M Johnson

\section{SUBSCRIPTION INFORMATION}

ISSN 0960-9768 4 issues Vol 11992

Member rate $\quad f 20$ (UK) $f 22.50$ (Eur/O's) $\$ 42.50$

(RCN, Cancer Relief Macmillan Fund and other nursing organisations)

Individual rate 149 (UK) 15150 (Eur/O's) $\$ 90$ (USA)

Institudional rate $\mathrm{f79}$ (UK) 183 (Eur/O's) $\$ 145$ (USA)

FREE SAMPLE COPY OFFER!

\section{OR.- - - - - - - - - - \\ JOURNAL OF CANCER CARE}

Yes! Please send me a sample copy.

Name

Address

Postcode

Return to: Churchill Livingstone Journals

Robert Stevenson House

1-3 Baxter's Place, Leith Walk

92mocicano EDINBURGH, EHI 3AF, Scotland, UK 
to the general public in the French language. The BDC falls into this category. To comply with the legislation, one side of the brochure was printed in English and the other side in French. It is interesting to note that about $75 \%$ of our area's population report English as their first language. Of the remaining population, the breakdown is disbursed among 20 different languages, the highest portion of which is three per cent for the Chinese population. (Ellis, 1992) Members of the Chinese and Italian communities frequent the BDC. Most of these non-English speaking patients are accompanied by an interpreter, however, a Chinese or Italian language translation of the brochure would be useful.

A graphic design for the front panel was created to support the title and project the image of the centre. Artwork that was attractive, feminine and non-threatening was sought. Soft and delicate colours of pink, ivory and teal blue with black type were chosen to offset the technical nature of the brochure.

Coated paper was used to make the brochure lustrous and eye-catching. In terms of environmental considerations, recycled stock was used in the printing of the brochure, however in Toronto there is presently no recycling of coated paper, therefore the brochure itself is not recyclable.

\section{Use}

The brochure is currently being used in a number of ways. In the $\mathrm{BDC}$, it is used as a teaching tool to reinforce verbal instructions. In the radiology department, the brochure is used as background material and a springboard for discussion between the patient and $\mathrm{x}$-ray staff immediately prior to the needle localization procedure. New nurses are given the brochure to read as part of their orientation program. Copies of the brochure are kept in the surgeon's office and the outpatient procedure unit. The brochure has been displayed during lectures to second-year medical students about breast health and at an interdisciplinary cancer education conference.

\section{Lessons learned}

The references used in the development of the brochure were not acknowledged. Inclusion at the end of the brochure of suggestions for additional reading material would have been helpful information for some patients.

There is a typing error in the brochure. The constant review of the material over a year had resulted in the correction of the typing error only in our minds. The need for an objective lay person to critique the printer's proof is imperative. Also, only limited confiderice should be placed in the spell check function of a word processing program because it will not pick up errors in homonyms and grammar.

The decision on readability of the brochure was haphazard. Printed education materials available to patients must be matched to the reading and comprehension levels of individual patients (Stephens, 1992). The use of a valid readability formula, for example the SMOG index (National Institutes of Health, 1982), would help match the reading level of the printed needle localization/biopsy brochure with the reading level of the target population. The literacy problem cannot be ignored.

\section{References}

1. Chart, P.L., \& Taylor, G.A. (1991, July). Ensuring detection of breast cancer. The Canadian Journal of Diagnosis, 59-73.

2. Ellis, P. (1992, Summer). Learning more about our communities. Scanner, 2.

3. Habegger, D., \& Ellerhorst-Ryan, J.M. (1988). Needle localization for nonpalpable breast lesions. Oncol. Nurs Forum, 15(2), 192-193.

4. Instructions for Outpatient Surgery. Sunnybrook Health Science Centre, University of Toronto. (1988).

5. Meade, C., \& Wittbrot, R. (1988). Computerized readability analysis of written materials. Comp Nurs, 6, 30-35.

6. Moffat, M. (1992). Centre adopts new philosophy statement. Toronto-Bayview Tid Bits, 2(7), 1.
The presumption that individuals read at the level of completed formal education is often inaccurate (Meade \& Wittbrot, 1988). Readability testing should be used as the first step in pre-testing draft manuscripts, followed by individual questionnaires or interviews regarding material with target audiences (National Institutes of Health, 1989).

Although we never validated the reading level with this population prior to the printing of the brochure, use of the SMOG readability formula measures it at an appropriate grade 12 level (NIH, 1982). During the writing phase of the brochure, the target audience was assessed at a grade 10 level. Due to the technical nature of the brochure, it was difficult to reduce the number of polysyllabic words. Feedback from patients, to date, however, has been positive in terms of readability.

The choice of printer was made by weighing several factors which included timeliness, quality, experience, cost, art, delivery and colour. In hindsight, it might have been productive to consider the cost/benefit of purchasing a desktop publishing program and laser printer that could be used for brochure production because the BDC intends to develop more brochures and keep existing brochures current.

The T-BRCC patient education committee has an interdisciplinary membership whose mandate is to oversee all matters pertaining to the education of patients at the centre. The approval process by the committee was slower than the interdisciplinary review process. In retrospect, better use could have been made of the committee by collaborating with them at an earlier date and discussing "time lines" that would have facilitated the speed of the process. Also, the editor's knowledge of the committee's criteria for approval of written material and written advice to authors would have been invaluable prior to the start of the project.

\section{Summary}

The brochure "Q \& A about Needle Localization/Biopsy" is used as a teaching tool to reinforce verbal instructions and help increase women's understanding of the investigation, their specific health care problem and self-care needs. With the trend to increasing outpatient surgery, caregivers are required to serve as an information clearinghouse for written patient education materials. It is critical, therefore, that they understand the brochure development process in order to adequately evaluate a brochure and/or develop information and instructional booklets. The BDC believes that the process used to develop a brochure is as important as the content or format of the brochure. In fact, the consultative process, albeit time-consuming, will ensure accurate content and ownership. Interdisciplinary team writing of the brochure encouraged professional collaboration and team-building and resulted in an accurate and comprehensive finished product.

Reaction to the brochure has been positive. Copies have been requested by colleagues from all the four areas involved. Continued use of the brochure as display material at professional conferences and sales of the generic brochure to other clinics are now under consideration.

\section{Acknowledgement}

A special acknowledgement to Pam Chart, medical coordinator, $B D C$, and Stephanie Burlein-Hall, former murse educator, T-BRCC, for their substantial help in developing the brochure.
7. National Institutes of Health. (1982, December). Pretesting in health communications: Methods, examples and resources for improving health messages and materials (NIH Publication No. 83-1493.

8. National Institutes of Health. (1989, April). Making health communication programs work: A planner's guide. (NIH Publication No. 89-1493).

9. Statistics Canada, Health and Welfare Canada, Provincial Cancer Registries, NClC. (1992) Canadian Cancer Statistics.

10. Stephens, S.T. (1992). Patient education materials: Are they readable? Oncol Nurs Forum 19(1), 83-85.

11. The Health Goals Committee of the Premier's Council on Health Strategy. (1991). Toward health outcomes: Goals 2 and 4: Objectives and targets. Toronto, Ontario. 